\title{
Fluorescent PMMA/MEH-PPV Electrospun Nanofibers: Investigation of Morphology, Solvent, and Surfactant Effect
}

\author{
Aline P. Roque, ${ }^{1}$ Luiza A. Mercante, ${ }^{1}$ Vanessa P. Scagion, ${ }^{1,2}$ Juliano E. Oliveira, ${ }^{3}$ \\ Luiz H. C. Mattoso, ${ }^{1}$ Leonardo De Boni, ${ }^{4}$ Cleber R. Mendonca, ${ }^{4}$ Daniel S. Correa ${ }^{1,2}$ \\ ${ }^{1}$ Laboratório Nacional de Nanotecnologia para o Agronegócio (LNNA), Embrapa Instrumentação, 13560-970, São Carlos, \\ São Paulo, Brazil \\ ${ }^{2}$ Centro de Ciências Exatas e de Tecnologia, Universidade Federal de São Carlos (UFSCar), 13565-905, São Carlos, São Paulo, \\ Brazil \\ ${ }^{3}$ Departamento de Engenharia de Materiais (DEMAT), Universidade Federal da Paraíba (UFPB), 58051-900, João Pessoa, \\ Paraíba, Brazil \\ ${ }^{4}$ Instituto de Física de São Carlos, Universidade de São Paulo (USP), 13560-970, São Carlos, São Paulo, Brazil \\ Correspondence to: D. S. Correa (E-mail: daniel.correa@embrapa.br)
}

Received 24 June 2014; revised 1 August 2014; accepted 4 August 2014; published online 22 August 2014

DOI: $10.1002 /$ polb.23574

ABSTRACT: Electrospinning is a powerful technique to produce nanofibers of tunable diameter and morphology for medicine and biotechnological applications. By doping electrospun nanofibers with inorganic and organic compounds, new functionalities can be provided for technological applications. Herein, we report a study on the morphology and optical properties of electrospun nanofibers based on the conjugated polymer poly[2-methoxy-5-(2-ethylhexyloxy)-1,4-phenylenevinylene] (MEH-PPV) and poly(methylmethacrylate) (PMMA). Initially, we investigate the influence of the solvent, surfactant, and the polymer concentration on electrospinning of PMMA. After determining the best conditions, $0.1 \%$ MEH-PPV was added to obtain fluorescent nanofibers. The optical characterizations display the successful impregnation of MEH-PPV into the PMMA fibers without phase separation and the preservation of fluorescent property after fiber electrospinning. The obtained results show the ability of the electrospinning approach to obtain fluorescent PMMA/MEH-PPV nanofibers with potential for optical devices applications. (C) 2014 Wiley Periodicals, Inc. J. Polym. Sci., Part B: Polym. Phys. 2014, 52, 1388-1394

KEYWORDS: fibers; nanotechnology; optics
INTRODUCTION Nanostructured materials, including nanoparticles, nanofibers, nanowires and ultrathin films, play a crucial role in fields such as biotechnology, medicine, and organic electronics. ${ }^{1}$ Among techniques to produce nanomaterials, electrospinning stands out due to the feasibility for producing various functional nonwoven fibers with tunable diameters and shapes. The driving force of interest for this technique is the possibility of producing inorganic and polymeric fibers with potential applications as tissue scaffolds, supports for enzymes and catalysts, filtration media, electronic, and optical devices. ${ }^{2}$ Electrospun polymer nanofibers could also be used for developing functional sensors, thanks to the high surface area of nanofibers that improves sensors sensitivity. ${ }^{3}$ The feasibility of combining compounds with desirable functionalities on the fibers can also be exploited in several technological applications. ${ }^{4} \mathrm{~A}$ recent example in this field was reported by Min et al., where a highly sensitive and selective optical chemical sensing of $\mathrm{Cu}$ (II) has been obtained by electrospinning rhodamine dye doped poly(ether sulfones). ${ }^{5}$

Incorporation of optoelectronically active materials, such as conjugated polymers and/or quantum dots, into electrospun nanofibers is also an appealing method to control the optical and electronic properties of devices at the nanometer scale. ${ }^{6,7}$ One of the conjugated polymers exhibiting fluorescent properties that has received significant interest is poly(1,4-phenylenevinylene) (PPV) as well as its derivatives, due to their potential uses as organic light-emitting diodes (LEDs) and photovoltaic devices. ${ }^{8}$ One of the most interesting members of the PPV family is poly[2-methoxy-5-(2-ethylhexyloxy)-1,4-phenylenevinylene] (MEH-PPV), because of its improved solubility and decreased intermolecular interaction in comparison with traditional PPV, as a result of the 
introduction of side chains. ${ }^{9}$ Recent efforts have been made to fabricate MEH-PPV-based nanofibers. ${ }^{10}$ For example, in electrospun MEH-PPV/molecular sieve composite nanofibers, the fluorescence spectrum is blue-shifted compared with that of the thin films and solutions, presumably due to the reduction of the degree of MEH-PPV aggregation in the nanofibers. ${ }^{11}$ Optoelectronic studies on the electrospun nanofibers made of MEH-PPV and polythiophene revealed that the energy transfer between the two components depends on the detailed morphologies of the nanofibers. ${ }^{12}$ Despite these results, fabrication of electrospun fibers of conjugated polymers is still a challenging process. Therefore, it is of interest to determine optimal conditions for electrospinning nanofibers containing low MEH-PPV concentrations with good morphology and intense photoluminescent properties.

In this work, we report the systematic study of PMMA and MEH-PPV-doped PMMA electrospun fibers. By optimizing the process conditions (polymer concentration and solvent), fibers with controlled diameter and morphology and free of defects were obtained at relatively lower concentration of PMMA and 0.1\% MEH-PPV. The surface morphology was characterized by scanning electron microscopy (SEM) and Fourier transform infrared (FTIR) spectroscopy. The thermal stabilities and thermal behaviors of the fibers were explored by thermal gravimetric analysis (TGA) and differential scanning calorimetry (DSC). The optical properties of PMMA/ MEH-PPV fibers were also investigated, revealing that the fibers retain the photoluminescent properties of the conjugated polymer. Such composite fibers are potential candidates for red-light device applications, such as LEDs, flat panel displays, photovoltaic cell, and optical sensors.

\section{EXPERIMENTAL}

\section{Materials}

Poly(methylmethacrylate) (PMMA, $\left.M_{\mathrm{w}}=350,000\right)$, poly[2methoxy-5-(2-ethylhexyloxy)-1,4-phenylenevinylene] (MEHPPV, $\left.M_{\mathrm{w}}=40,000-70,000\right)$, and hexadecyltrimethylammonium bromide (CTAB) were purchased from Sigma-Aldrich. The solvents including chloroform and 1,2-dichloroethane were purchased from Synth Chemical (São Paulo, Brazil). All the chemicals were used as received.

\section{Sample Preparations}

Polymer solutions were prepared by dissolving 5, 7, and $20 \%$ (w/v) PMMA in chloroform and 1,2-dichloroethane. The solutions were stirred for $\sim 4 \mathrm{~h}$ at room temperature. The PMMA/MEH-PPV solution was prepared using chloroform as solvent, in concentrations of $5 \%(\mathrm{w} / \mathrm{v})$ PMMA and $0.1 \%$ (w/w) MEH-PPV. CTAB surfactant was also added to the solution $[10 \%(\mathrm{w} / \mathrm{w})]$ to help obtaining PMMA/MEH-PPV nanofibers with smaller diameters and smoother surface. Solutions were prepared by dissolving all chemicals together and stirring for $4 \mathrm{~h}$ at room temperature.

\section{Electrospinning Process}

PMMA and PMMA/MEH-PPV electrospun nanofibers were obtained by using an electrospinning apparatus at a feed rate of $0.15 \mathrm{~mL} \mathrm{~h}^{-1}$ and an electric voltage of $20 \mathrm{kV}$. A working distance of $6 \mathrm{~cm}$ was kept between the syringe and the metallic collector. The inner diameter of steel needle was fixed at $1.2 \mathrm{~mm}$.

\section{Physico-Chemical Characterization}

The morphology of the fibers was evaluated by a SEM (JEOL 6510) operating at $10 \mathrm{kV}$. Fiber diameters were measured using image analysis software (Image J, National Institutes of Health). For each experiment, average fiber diameter and distribution were determined from $\sim 100$ random measurements from fiber micrographs. FTIR spectra were recorded on a Spectrum 1000 (Perkin Elmer) spectrometer. A total of 64 scans were collected with a resolution of $2 \mathrm{~cm}^{-1}$. The FTIR spectra were recorded in transmission mode using thick films of electrospun polymer nanofibers, which were deposited onto a silicon wafer.

TGA were performed on a Q500 TA thermogravimetric analyzer under nitrogen atmosphere, at a flow rate of $20 \mathrm{~mL}$ $\min ^{-1}$. Samples were scanned from room temperature up to $600{ }^{\circ} \mathrm{C}$ at a scanning rate of $10{ }^{\circ} \mathrm{C} \mathrm{min}^{-1}$ using platinum pans. DSC analyses were performed on a Q100 TA calorimetric analyzer under nitrogen atmosphere, at a flow rate of $20 \mathrm{~mL} \mathrm{~min}^{-1}$. The samples were heated from -80 to $200{ }^{\circ} \mathrm{C}$ at a scanning rate of $10{ }^{\circ} \mathrm{C} \mathrm{min}^{-1}$ using aluminum pans.

Fluorescence confocal images of MEH-PPV/PMMA nanofibers were obtained with a Carl Zeiss-LSM510 confocal laser scanning microscope and the photoluminescence (PL) spectrum was collected using a Hitachi fluorometer, model F-7000. For the confocal microscopy and the PL measurements, the nanofibers were electrospun directly on glass substrates.

\section{RESULTS AND DISCUSSION}

Studies have shown that the nature of the solvent and the polymer concentration can significantly affect the electrospinning process and thereby the diameter and morphology of the resulting fibers. ${ }^{13}$ Hence, the effect of these parameters on electrospinning of PMMA was systematically investigated. Three different concentrations (5, 7, and 20\%) and two different organochloride solvents, including chloroform and 1,2-dichloroethane were used to evaluate the effect on the PMMA fiber formation. These solvents were chosen because they were good solvents for PMMA, ${ }^{14}$ which means that the polymer-solvent interactions are more important than polymer-polymer interactions.

The SEM images of the electrospun fibers obtained from the PMMA solutions with different concentrations in 1,2dichloroethane and chloroform are shown in Figure 1. The PMMA electrospun fibers obtained from lower polymer concentration solutions (5 and 7\%) are ribbon like with beads along the fiber direction, and display a range of sized nanopores along the fiber surface [Fig. 1(a-d)]. Polymeric ribbon morphology obtained by electrospinning process can be explained by collapse of the skin on the jet during stretching. ${ }^{15}$ Porous electrospun fiber morphology is probably due 

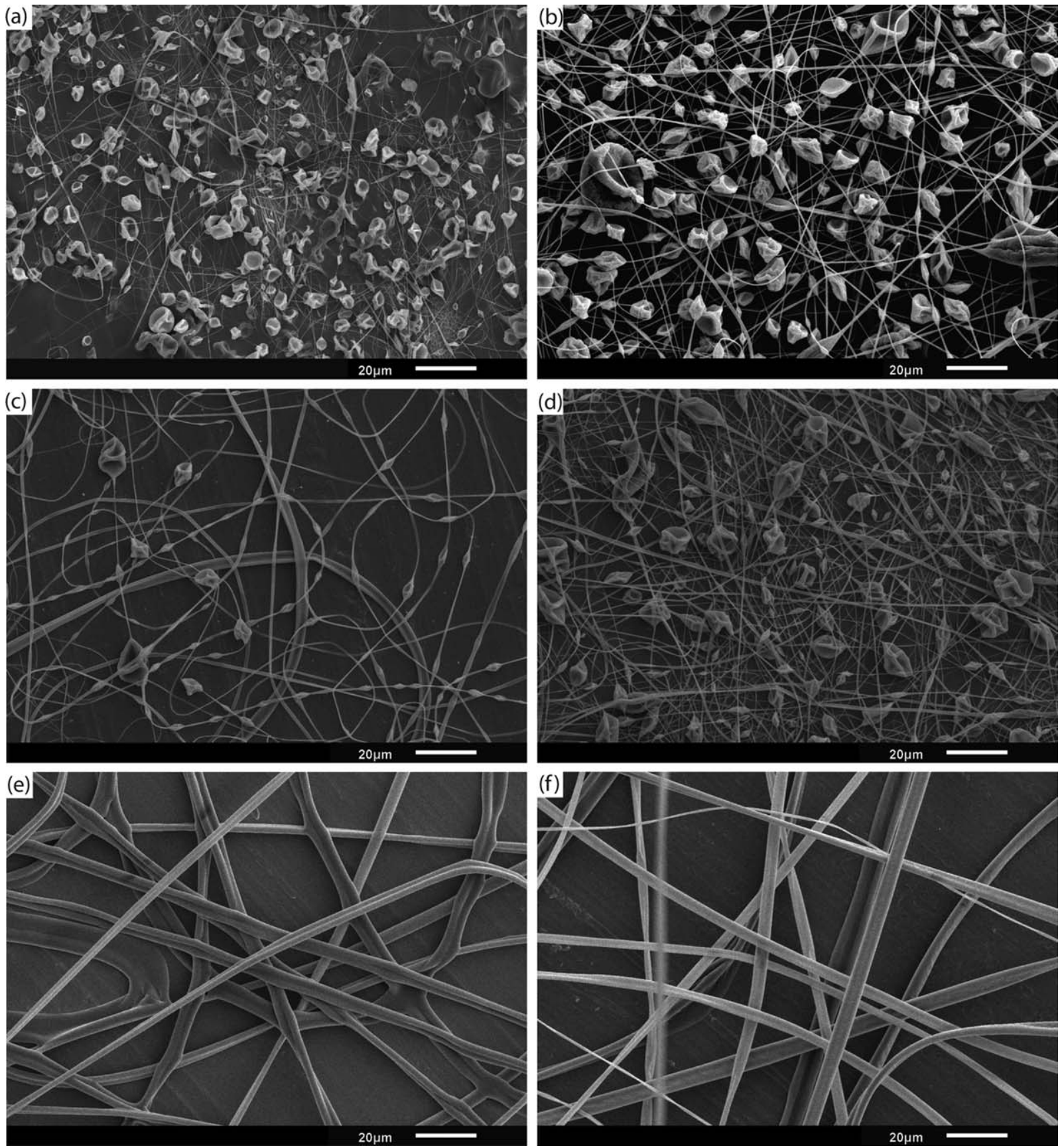

FIGURE 1 SEM images of PMMA nanofibers using chloroform: (a) 5; (c) 7; and (e) 20\% (w/v) and 1,2-dichloroethane: (b) 5; (d) 7; and (f) $20 \%(w / v)$.

to the effects of relative humidity, which is also influenced by polymer hydrophobicity, solvent properties, and applied charge. ${ }^{16}$ On the other hand, uniform and continuous fibers were formed when the concentration was 20\% (w/v) [Fig. $1(\mathrm{e}, \mathrm{f})]$. By increasing the polymer concentration, there is an increase in chain entanglements, thereby increasing the viscosity of the polymer solution, which overcomes the surface tension of the polymer solution, resulting in fewer beads. ${ }^{17}$

Table 1 summarizes average diameters of the as-spun fibers obtained. It is possible to observe that as the solution con- centration increases, the fiber diameter also increases due the higher solution viscosity. The as-spun fibers from PMMA solution in chloroform presented higher diameters than those obtained in 1,2-dichloroethane. In the electrospinning technique, electrical forces affect the stretching charged jet; for instance, high dielectric constant enhances the charge density at the surface of the jet, allowing better stretching and uniform formation of fibers with appropriate morphology. The greater dielectric constant of 1,2-dichloroethane compared with that of chloroform is probably responsible for the smaller diameters of the obtained fibers, because 
TABLE 1 Fiber Diameters Obtained Using Different Solvent and Polymer Concentrations

\begin{tabular}{llc}
\hline & $\begin{array}{c}\text { Polymer } \\
\text { Concentration } \\
(\% \mathrm{w} / \mathrm{v})\end{array}$ & $\begin{array}{c}\text { Mean Diameter } \\
\text { Solvent }\end{array}$ \\
\hline 1,2-Dichloroethane & 5 & $110 \pm 58$ \\
& 7 & $570 \pm 216$ \\
\hline Chloroform & 20 & $2170 \pm 490$ \\
& 5 & $449 \pm 135$ \\
& 7 & $590 \pm 188$ \\
& 20 & $2250 \pm 510$
\end{tabular}

greater dielectric constant leads to greater Coulombic repulsion force (being responsible for the stretching of the charged jet) and electrostatic force (being responsible for carrying the charged jet to the collective target). ${ }^{18}$

Aiming at obtaining thinner and bead-free fibers, 10\% (w/ w) of cationic surfactant, dodecyltrimethylammonium chloride (CTAB), was added to the $5 \%(\mathrm{w} / \mathrm{v})$ PMMA solution. One of the most serious problems in application of electrospinning is the presence of beads on the fibers, which impair fibers final properties when fabricated by nonwoven approaches. ${ }^{19}$ Additives for facilitating bead-free electrospun fibers include salts and surfactants. ${ }^{20}$ Although salts may increase the electrical conductivity of the solution to be spun, they have limited effect on the surface tension and viscosity of the polymer solution. In addition, the selection of salt is limited by the fact that the solvents used in most of the cases are organic. Surfactants, on the other hand, reduce the surface tension and viscosity of the solution and also optimize the charge density of the polymer solution. Hence, in order to reduce the beads and fiber diameters, CTAB was chosen as additive in our case. Between the two solvents investigated, 5\% (w/v) PMMA solution in chloroform was chosen as the model solution, because CTAB and MEH-PPV

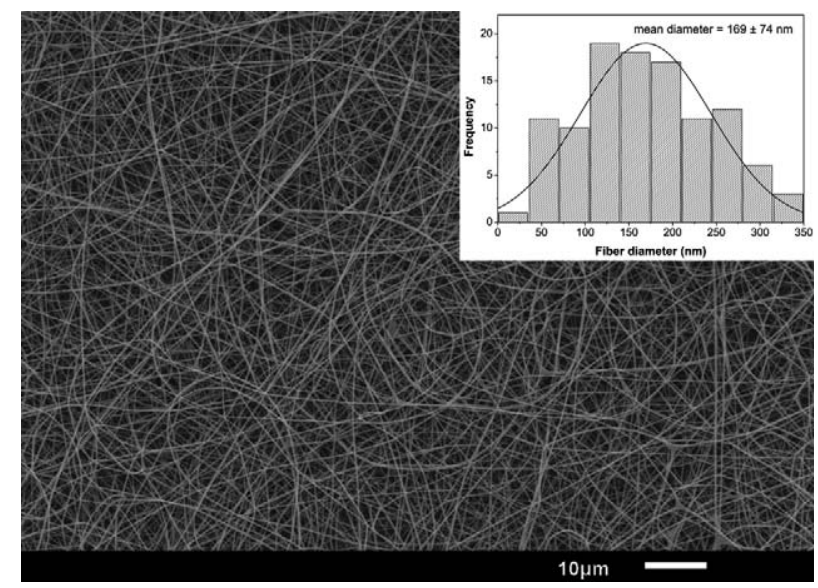

FIGURE 2 SEM image of PMMA nanofibers achieved in the presence of $10 \%(w / w)$ CTAB. The inset shows the histogram of size distribution. in the presence of PMMA were better solubilized into a clear solution using this solvent.

The use of $10 \%(\mathrm{w} / \mathrm{w}$ ) CTAB yielded fibers with regular and smooth surface morphologies and bead-free fibers (see Fig. 2), with may play an important role for technological applications. The obtained results reveal that addition of CTAB strongly helped to decrease nanofibers diameters $(\sim 169 \mathrm{~nm})$ from the PMMA in chloroform solution (see Table 1). Besides, the addition of CTAB also improved the electrospinnability of the solutions, being responsible for an increase in the mass throughput of the as-spun products, most likely due to the increased electrostatic force. ${ }^{21}$

After determining the optimized conditions for electrospinning PMMA, $0.1 \%(\mathrm{w} / \mathrm{w})$ MEH-PPV was added to the main solution to obtain luminescent nanofibers. SEM image displayed in Figure 3 reveal that no significant changes were observed on fibers diameter, except a decrease on the size distribution of nanofibers diameters after MEH-PPV addition (inset Fig. 3).

To confirm the incorporation of MEH-PPV in PMMA nanofibers, the samples were analyzed by FTIR spectroscopy (Fig. 4). Figure 4(a) shows that the pure PMMA nanofibers present peaks at $1722 \mathrm{~cm}^{-1} \quad(\mathrm{C}=0$ stretching vibration), $1448 \mathrm{~cm}^{-1}$ (skeletal $\mathrm{CH}_{2}$ deformation), 1272 and $1244 \mathrm{~cm}^{-1}$ (C-C-O in the ester group) and 1194 and $1148 \mathrm{~cm}^{-1}$ (C-O-C of the methoxy group). ${ }^{22}$ For the PMMA nanofibers modified with MEH-PPV [Fig. 4(b)] it is possible to observe, in addition to the same peaks observed for pure PPMA, a shoulder located at $1650 \mathrm{~cm}^{-1}$ corresponding to the $\mathrm{C}=\mathrm{C}$ stretch of the vinylene group, and the peak at $1064 \mathrm{~cm}^{-1}$ associated to the alkyl-oxygen stretch, characteristics of MEH-PPV. ${ }^{23}$ In addition, the peak attributed to the $\mathrm{C}=0$ of PMMA shifts to $1734 \mathrm{~cm}^{-1}$, indicating the existence of chemical interactions between the polymers. ${ }^{24}$

To study the thermal properties of neat PMMA and PMMA/ MEH-PPV fibers, both TGA and DSC were carried out.

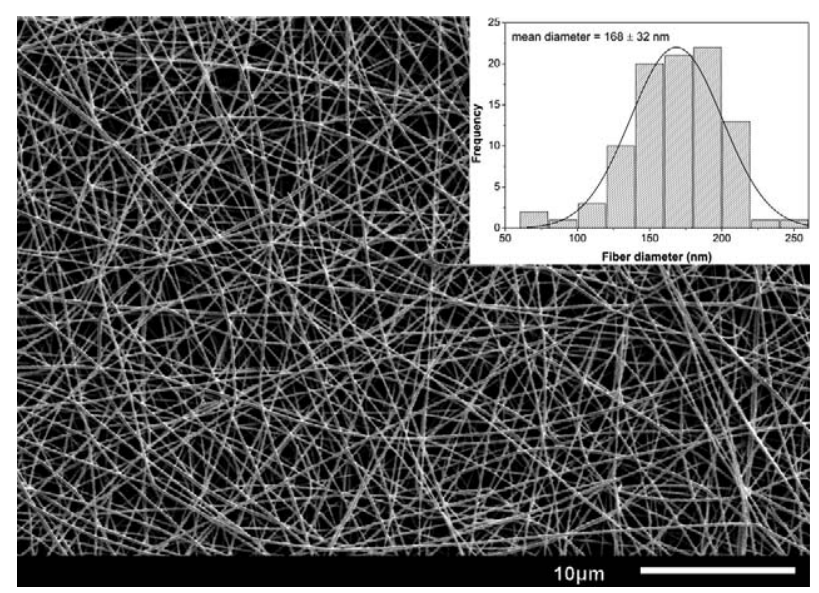

FIGURE 3 SEM image of PMMA/MEH-PPV nanofibers. The inset shows the histogram of size distribution. 


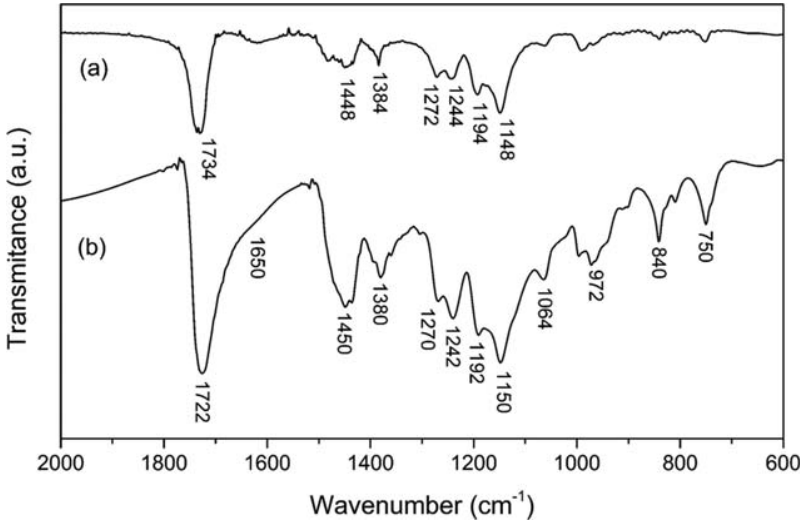

FIGURE 4 FTIR spectra of (a) PMMA and (b) PMMA/MEH-PPV nanofibers.

Figure 5(a) shows the TGA curves of the samples. Both PMMA and PMMA/MEH-PPV exhibit two distinct thermal behaviors: the first weight loss, starting at room temperature and extending up to $270{ }^{\circ} \mathrm{C}$, results from the evaporation of residual solvent and the removal of low molecular weight molecules (CTAB), while the second weight loss, with maximum derivative at $350{ }^{\circ} \mathrm{C}$, is due to the complete decomposi-
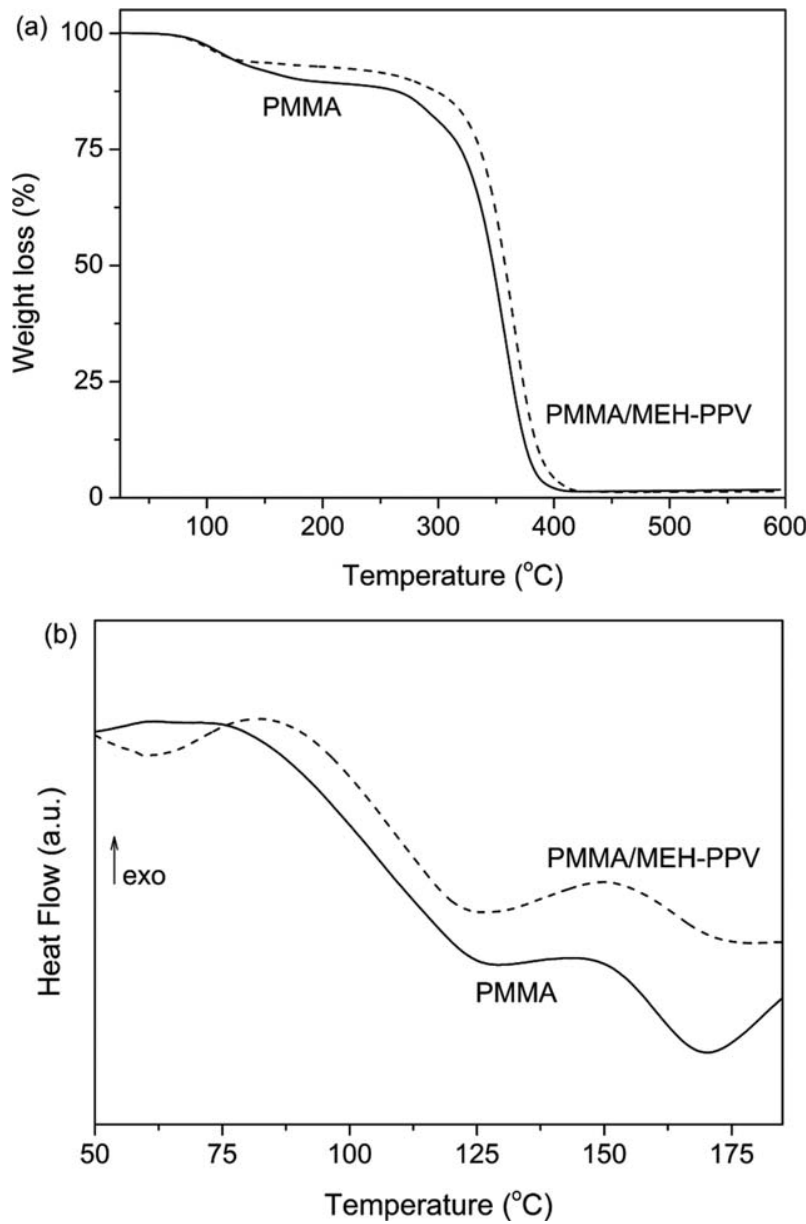

FIGURE 5 (a) TGA and (b) DSC curves of PMMA (solid line) and PMMA/MEH-PPV (dashed line) nanofibers. tion of PMMA. $^{25}$ In comparison, the PMMA/MEH-PPV nanofibers show a slightly higher $\left(10{ }^{\circ} \mathrm{C}\right.$ increment $)$ improved thermal stability, which may be attributed to the interaction between PMMA and MEH-PPV.

Figure 5(b) shows DSC curves for PMMA and PMMA/MEHPPV fibers. It is possible to observe that PMMA fibers display a glass transition temperature $\left(T_{\mathrm{g}}\right)$ at $128{ }^{\circ} \mathrm{C}$, while PMMA/ MEH-PPV fibers showed a slightly lower $T_{\mathrm{g}}$ of $124{ }^{\circ} \mathrm{C}$. The incorporation of MEH-PPV also causes a subtle change on the melting point temperature $\left(T_{\mathrm{m}}\right)$, which increases from 170 to $177{ }^{\circ} \mathrm{C}$. The lower $T_{\mathrm{g}}$ and higher $T_{\mathrm{m}}$ could also be attributed to the interaction between MEH-PPV and PMMA and indicates a good miscibility of the two polymers, as expected, once only small amounts of MEH-PPV (0.1\%) was added to the PMMA solution.

In Figure 6(a), optical microscope image of typical MEH-PPVcontaining PMMA nanofibers is displayed, while Figure 6(b) shows fluorescence microscope image evidencing the red light uniformly emitted from the nanofibers membrane. Figure 6(c) displays a confocal laser scanning microscopy (CLSM) image (artificial color) of the PMMA/MEH-PPV nanofibers, obtained using laser excitation wavelength at $458 \mathrm{~nm}$. The CLSM images confirmed the emission of MEHPPV along the electrospun nanofibers.

The fluorescence of MEH-PPV is strongly dependent on its aggregation states/conditions. ${ }^{6,26,27}$ The emission from isolated MEH-PPV polymeric chains (such as those existing in extremely dilute solutions and/or nanoparticles with sizes of a few nanometers) mainly originate from the optical transitions of the excited states in separated conjugated chain segments. The lengths and structures of those segments are determined by both, the chemical structures and defects in the conformations of each individual MEH-PPV chain. ${ }^{28}$ Those MEH-PPV conjugated chain segments can be photoexcited to generate intra-chain excitations, which can emit fluorescence at a wavelength centered around $560 \mathrm{~nm} \cdot{ }^{27,29}$ The emission from aggregated MEH-PPV polymers occurs at longer wavelengths; and such emission is affected by the interchain interactions (including $\pi-\pi$ interactions and chain entanglements), which are sensitive to the molecular weight of MEH-PPV, solvent of the solution, annealing temperature, and film preparation parameters. ${ }^{26}$ Figure $6(\mathrm{~d})$ shows the PL spectra of PMMA/MEH-PPV nanofibers, whose spectrum presents the same features of neat MEH-PPV film. ${ }^{6}$ Such result indicates that the PL property of MEH-PPV was not greatly affected by the presence of PMMA. However, when compared with the MEH-PPV solution, the spectrum of the nanofibers exhibits a blue shift $\left(\lambda_{\text {máx }}=550 \mathrm{~nm}\right)$. A possible explanation for this effect is that PMMA and CTAB may serve as steric spacers that hinder MEH-PPV aggregation, which might prevent $\pi-\pi$ stacking to some extent during electrospinning. ${ }^{23}$

Our results show that MEH-PPV can be effectively impregnated into the PMMA fibers without phase separation, and that the fluorescent property of MEH-PPV was preserved 

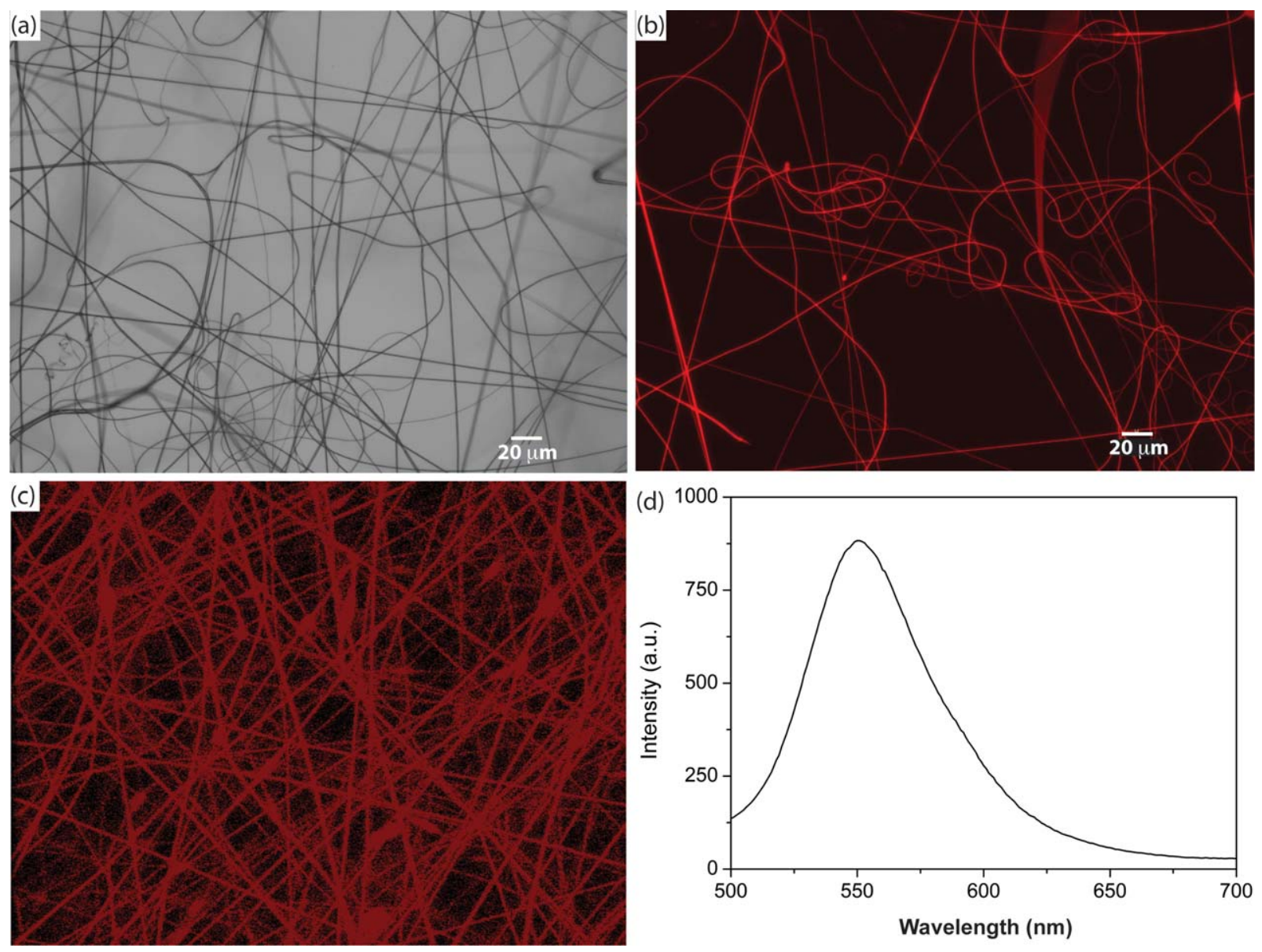

FIGURE 6 (a) optical microscopy image, (b) fluorescence microscope image, (c) confocal microscopy image, and (d) PL spectra of typical PMMA/MEH-PPV nanofibers. [Color figure can be viewed in the online issue, which is available at wileyonlinelibrary.com.]

after fiber electrospinning. Such nanofibers with controlled diameter and morphology and free of defects are important for optical applications, including optical devices and chemical sensors.

\section{CONCLUSIONS}

Electrospun PMMA fibers with average diameters ranging from $110 \mathrm{~nm}$ to $2.25 \mu \mathrm{m}$ were successfully prepared from solutions in chloroform and 1,2-dichloroethane. Irrespective of the solvent, an increase in polymer concentration resulted in an increase of average fiber diameter with less possibility for bead formation. Addition of CTAB surfactant drastically improves the solution spinnability, even for low concentration solutions, leading to nanofibers with good morphology, small diameters and controlled size. Incorporation of $\mathrm{MEH}-$ PPV leads to nanofibers with essentially the same physicochemical properties of neat PMMA fiber. Besides, optical characterizations showed that MEH-PPV was effectively impregnated into the PMMA fibers without phase separation, and that the fluorescent property of MEH-PPV was preserved after fiber electrospinning. The results presented here demonstrate that fibers with good morphology and controlled diameter can be obtained by the electrospinning approach to obtain fluorescent nanofibers with potential application for optical devices and chemical sensors. In addition, by altering the insulating polymeric matrix (PMMA) by a conducting one, the obtained nanofibers could also be applied for electronic applications.

\section{ACKNOWLEDGMENTS}

The authors thank financial support from FAPESP, CNPq, CAPES, MCTI, and EMBRAPA from Brazil.

\section{REFERENCES AND NOTES}

1 (a) F. Habelhames, L. Lamiri, W. Zerguine, B. Nessark, Mater. Sci. Semicond. Process. 2013, 16, 727-731; (b) H. Gleiter, Acta Mater. 2000, 48, 1-29.

2 (a) S. Agarwala, A. Greinera, J. H. Wendorff, Prog. Polym. Sci. 2013, 38, 963-991; (b) E. Llorens, E. Armelin, M. M. PérezMadrigal, L. J. del Valle, C. Alemán, J. Puiggali', Polymers 2013, 5, 1115-1157; (c) T. J. Sill, H. A. von Recum, Biomaterials 2008, 29, 1989-2006.

3 (a) Y. Lv, Y. Zhang, Y. Du, J. Xu, J. Wang, Sensors 2013, 13, 15758-15769; (b) J. E. Oliveira, V. P. Scagion, V. Grassi, D. S. 
Correa, L. H. C. Mattoso, Sens. Actuators B 2012, 171, 249-255; (c) H. Q. Liu, J. Kameoka, D. A. Czaplewski, H. G. Craighead, Nano Lett. 2004, 4, 671-675.

4 (a) Y. Zhang, L. Luo, Z. Zhang, Y. Ding, S. Liu, D. Deng, H. Zhao, Y. Chen, J. Mater. Chem. B 2014, 2, 529-535; (b) A. Frenot, I. S. Chronakis, Curr. Opin. Colloid Interfaces Sci. 2003, 8, 64-75.

5 M. Min, X. Wang, Y. Chen, L. Wang, H. Huang, J. Shi, Sens. Actuators B 2013, 188, 360-366.

6 Z. Zhu, L. Zhang, S. Smith, H. Fong, Y. Sun, D. Gosztola, Synth. Met. 2009, 159, 1454-1459.

7 (a) D. S. Correa, E. S. Medeiros, J. E. Oliveira, L. G. Paterno, L. H. C. Mattoso, J. Nanosci. Nanotechnol. 2014, 14, 1-19; (b) M. Bashouti, W. Salalha, M. Brumer, E. Zussman, E. Lifshitz, ChemPhysChem. 2006, 7, 102-106.

8 (a) V. K. Chandra, M. Tiwari, B. P. Chandra, M. Ramrakhiani, Synth. Met. 2011, 161, 460-465; (b) N. S. Sariciftci, D. Braun, C. Zhang, V. I. Srdanov, A. J. Heeger, G. Stucky, F. Wudl, Appl. Phys. Lett. 1993, 62, 585-587.

9 (a) W. Zhong, F. Li, L. Chen, Y. Chen, Y. Wei, J. Mater. Chem. 2012, 22, 5523-5530; (b) M. S. Su, H. C. Su, C. Y. Kuo, Y. R. Zhouand, K. H. Wei, J. Mater. Chem. 2011, 21, 6217-6224; (c) D. S. Correa, L. de Boni, D. T. Balogh, C. R. Mendonça, Adv. Mater. 2007, 19, 2653-2656; (d) S. J. Chung, G. S. Maciel, H. E. Pudavar, T. C. Lin, G. S. He, J. Swiatkiewicz, P. N. Prasad, D. W. Lee, J. I. Lin, M. Menard, J. Phys. Chem. A 2002, 106, 75127520; (e) G. Yu, J. Gao, J. C. Hummelen, F. Wudl, A. J. Heeger, Science 1995, 270, 1789-1791.

10 (a) U. Balderas, C. Falcony, I. Moggio, E. Arias, M. Mondragón, Polymer 2013, 54, 2062-2066; (b) R. Zhou, W. Chen, X. Jiang, S. Wang, Q. Gong, Appl. Phys. Lett. 2010, 96, 133309; (c) H.-C. Chen, C.-T. Wang, C.-L. Liu, Y.-C. Liu W.-C. Chen, J. Polym. Sci. Part B: Polym. Phys. 2009, 47, 463-470; (d) P. Wutticharoenmongkol, P. Supaphol, T. Srikhirin, T. Kerdcharoen, T. Osotchan, J. Polym. Sci. Part B: Polym. Phys. 2005, 43, 1881-1891.

11 S. Madhugiri, A. Dalton, J. Gutierrez, J. P. Ferraris, K. J. Balkus, J. Am. Chem. Soc. 2003, 125, 14531-14538.

12 A. Babel, D. Li, Y. N. Xia, S. A. Jenekhe, Macromolecules 2005, 38, 4705-4711.
13 K. H. Lee, H. Y. Kim, M. S. Khil, Y. M. Ra, D. R. Lee, Polymer 2003, 44, 1287-1294.

14 H. Dong, V. Nyame, A. G. MacDiarmid, W. E. Jones, J. Polym. Sci. Part B: Polym. Phys. 2004, 42, 3934-3942.

15 S. Koombhongse, W. Liu, D. H. Reneker, J. Polym. Sci. Part B: Polym. Phys. 2001, 39, 2598-2606.

16 (a) R. M. Nezarati, M. B. Eifert, E. Cosgriff-Hernandez, Tissue Eng. Part C Methods 2013, 19, 810-819; (b) L. H. C. Mattoso, R. D. Offeman, D. F. Wood, J. W. Orts, E. S. Medeiros, Can. J. Chem. 2008, 86, 590-599.

17 (a) H.-S. Bae, A. Haider, K. M. K. Selim, D.-Y. Kang, E.-J. Kim, I.-K. Kang, J. Polym. Res. 2013, 20, 1-7; (b) Y. Liu, J. H. He, J. Yu, H. Zeng, Polym. Int. 2008, 57, 632-636.

18 L. Wannatong, A. Sirivat, P. Supaphol, Polym. Int. 2004, 53, 1851-1859.

19 K. Yosuke, S. Masataka, T. Takashi, K. Kiyohito, Polym. Eng. Sci. 2010, 50, 1788-1796.

20 A. Aluigi, A. Varesano, A. Montarsolo, C. Vineis, F. Ferrero, G. Mazzuchetti, C. Tonin, J. Appl. Polym. Sci. 2007, 104, 863870.

21 C. J. Luo, M. Nangrejo, M. Edirisinghe, Polymer 2010, 51, 1654-1662.

22 C. C. Zhang, X. Li, Y. Yang, C. Wang, Appl. Phys. A 2009, 97, 281-285.

23 Q. Zhao, Y. Xin, Z. Huang, S. Liu, C. Yang, Y. Li, Polymer 2007, 48, 4311-4315.

24 S. Pelfrey, T. Cantu, M. R. Papantonakis, D. L. Simonson, R. A. McGill, J. Macossay, Polym. Chem. 2010, 1, 866-869.

25 Z. Dong, S. J. Kennedy, Y. Wu, J. Power Sources 2011, 196, 4886-4904.

26 Y. Shi, J. Liu, Y. Yang, J. Appl. Phys. 2000, 87, 4254-4263.

27 J. K. Grey, D. Y. Kim, B. C. Norris, W. L. Miller, P. F. Barbara, J. Phys. Chem. B 2006, 110, 25568-25572.

28 M. Yan, W. W. L. J. Rothberg, B. R. Hseih, Phys. Rev. Lett. 1995, 75, 1992-1995.

29 O. Mirzov, I. G. Scheblykin, Phys. Chem. Chem. Phys. 2006, 8, 5569-5576. 